\title{
Activity-Travel Behaviour, and Daily and Global Well-Being
}

\author{
Muhammad Isran Ramli ${ }^{1, *}$ and Dimas Endrayana Dharmowijoyo ${ }^{2,3}$ \\ ${ }^{1}$ Department of Civil Engineering, Universitas Hasanuddin, Indonesia \\ ${ }^{2}$ Department of Civil and Environmental Engineering, Universiti Teknologi Petronas, Malaysia \\ ${ }^{3}$ School of Architecture, Planning and Policy Development, Institut Teknologi Bandung (ITB), \\ Indonesia
}

\begin{abstract}
Using a hierarchical SEM and multidimensional 3-week household time-use and activity diary, this study investigated how interaction of individuals' daily travel parameters, time-use and activity participation and percentage of undertaking passive leisure within various activity participation, life circumstances, and geographical conditions shape individuals' daily and global subjective well-being. This study confirms that life circumstances insignificantly shape people's well-being as argued as well in previous studies. Moreover, daily subjective well-being or people daily context in which contains how people organizes their daily activitytravel behaviour positively shape people life satisfaction as hypothesised. This study also confirms that different daily activity participation tends to shape different level of people's daily subjective well-being. Spending more time-use for leisure, sport and grocery shopping tends to positively correlate with having better daily subjective well-being. Having better mental and social health are found to positively shape people's daily and global wellbeing, respectively. For policy implementations, this study can say that providing more opportunities for undertaking out-of-home activities such as out-of-home leisure, sport and grocery shopping with time-use policy and denser land use planning.
\end{abstract}

\section{Introduction}

Individuals aim to satisfy their needs and desires shaped by their constraints in term of physical, economics, institutional, social and cultural contexts. On daily basis, as a result of interactions among individuals' needs, desires and constraints (broken down into capability, coupling and authority constraints), individuals will organise a set of activities. Undertaking a particular activity may experience human on different state of pleasure or displeasure. Leisure, social and relaxing activities are indicated as the most enjoyable activities, whereas work, housework and commuting are rated as the less enjoyable activities than the former group of activities [1,2].

* Corresponding author: isranramli@unhas.ac.id 
Moreover, individuals tend to undertake a set of different activities both mandatory and discretionary, and in-home and out-of-home, during a day due to their personal and social characteristics.

If we assume that each activity would impact on a particular degree of well-being, individuals would have certain rating of their daily well-being through their experiences in engaging different set of activities and travels during a day either enjoyable or less enjoyable within a particular environment situation. There is a strong indication that individuals tend to trade-off in performing more pleasant and less pleasant activities during a day $[3,4,5,6]$ and during weekly activities [7, 8,9] for maintaining/maximizing their well-being on a particular level. Individuals may perform some activities and/or multi-tasking activities within their possible time-space constraints which may maximize their perceived well-being state $[3,4,5,6]$. Trade-off mechanisms in time geography research shows how workers and students reduce their time allocation for in-home maintenance activity when they spend more time on working and out-of-home leisure activities and travel for out-of-home discretionary activity purposes $[8,10)$. For weekly time-use and activity participation, someone will perform less travels or less size of activity space on weekends when they undertake other way around on weekdays [7,9]. For developed country case, any engagement on more fun activity such leisure activities will shape other activities with lower degree of fixity such as grocery shopping and undertaking household obligations [11]. From that perspective, individuals' daily well-being can be assumed as an accumulation of episode well-being due to individuals' participation on different activities during a day either enjoyable or less enjoyable activities influenced also by certain environment conditions. One type of activity cannot be representation of individuals' daily well-being. That is why, it is found no relation between individuals' episode well-being with individuals' daily experiences $[2,4,6]$. Exposure on having different set of projects and constraints on different day which lead individuals to have different set of activities on different day and to face different environmental conditions. This is an argument why individuals may have different state of well-being situations on different day.

Previous studies have investigated how individuals' episode level of well-being is influenced by individuals' life circumstances, activity-travel behaviour in term of social and time-geography perspectives, and built environment (geographical) conditions. However, previous studies rarely touched the inclusion of day-to-day of individuals' activity-travel behaviour. Individuals tend to have different set of activities on different day, which may also influence their daily level of subjective well-being and may also correlate with their well-being in certain episode of life. Moreover, previous studies ignored how multitasking activities on their daily activity-travel behaviour such as traveling with listening music and joining working activities with TV influence individuals' efforts in maximizing their wellbeing.

Furthermore, activity-travel behaviour research can also contribute how individuals' daily activity-travel behaviour and/or daily well-being shape long term processes including life satisfaction. Life satisfaction is a multi-dimension concept in which contains life circumstances (such as number of household, the appearance of dependent child/children, and household income) and daily situations including daily activity-travel behaviour, traffic or built environment conditions. However, life circumstances are found to have little impact on life satisfaction $[12,13]$. There is an adaptation process that makes individuals' life circumstances is little affecting their life satisfaction as a whole. On the other hand, the contexts either geographical or social or daily activity-travel behaviour contexts were found to shape people life satisfaction or global well-being [2]. Moreover, domain well-being such as health performance which may be defined as another level of capability of constraints in time-space prism theory, may shapes the life satisfaction. 
This study will apply a three-week household time-use and activity diary which covered multi-dimensional information such as household, physical activity and life style, individuals' subjective characteristics, time-use and activity diary and subjective well-being variables. This study will examine interactions among day-to-day variability of individuals' time-use and activity participation including multi-tasking activities, built environment conditions and life circumstances variables on individuals' subjective well-being on individuals' daily well-being. Some activities categorized as more enjoyable activities such as socializing and recreation activities or leisure activities are hypothesized to positively influence people's daily well-being [1]. Other variables such as subjective and objective geographical conditions are also hypothesized to significantly shape people's daily wellbeing. Furthermore, individuals' daily well-being in conjunction with individuals' daily time-use and activity participation including multitasking activities and travel parameters, life circumstances, and objective and subjective geographical conditions may shape individuals' global well-being or life satisfaction. Life circumstance such represented by socio-demographic variables may not significantly affect people life satisfaction. However, as argued in previous studies, daily subjective well-being and the contexts are hypothesized to significantly shape life satisfaction.

\section{The 2013 Bandung Metropolitan Area Dataset}

The BMA dataset includes multi-dimensional information such as household, physical activity and lifestyle, individual's subjective characteristics, time-use and activity diary, and subjective well-being data. The survey involved 732 individuals and 191 households from all over BMA for 21 consecutive days [14]. The household data section contained household composition, individuals' perception about how far his/her accommodation was from the city centre, public and transportation facilities, and built environment variables [14]. The profile of the samples used in this study is illustrated in Table 1.

The time-use and activity diary survey captured twenty-three in-home and out-of-home activity classifications, travel duration and mode characteristics, and multitasking activities for adults, young adults and children above seven years of age. In this study, time-use activity participation was classified into groups of mandatory and discretionary activities. The mandatory activities are classified as activities that are difficult to re-schedule [15] with higher temporal and spatial fixity (such as working, school and pick up/drop activities, 11), thus, dictating the individual's ability to perform the discretionary activities. Moreover, discretionary activities are defined as activities that are easy to re-schedule within time and space limitations [15] with higher temporal and spatial flexibility such as grocery shopping and leisure activities [11].

Multi-tasking activities were defined as concurrent activities which contained primary and secondary activities $[16,17]$ for satisfying different needs and desires at the same time. In this case, multi-tasking activities were defined as combining mandatory activities (such as work/school, eating, sleeping), maintenance activities (such as nursing, grocery shopping), and active leisure activities such as doing sport or reading a book with passive leisure activities, such as entertainment and socialising [17]. Socialising in this case was defined as meeting with other people such as with other household members, or non-household members. 
Table 1. Profile of the samples used in the study

\begin{tabular}{|l|c|}
\hline \multicolumn{1}{|c|}{ Variables } & $\begin{array}{c}\text { Percentage or } \\
\text { Mean }\end{array}$ \\
\hline Socio-demographic characteristics at individual level: & \\
Male & $52.10 \%$ \\
Worker and non-worker & $43.64 \%$ and $31.05 \%{ }^{1}$ \\
Is a dependent children (<= 14 years old) & $12.73 \%$ \\
Age (continuous) (years old) & 38.6 \\
Part of low income ( $<$ IDR 3 million/month) and medium income & \\
households (IDR 3-6 million/month) & $75.20 \%$ and $15.80 \%{ }^{1}$ \\
\hline Household characteristics: & 4.52 \\
Number of household members & 0.83 \\
Number of dependent children per household & 1.77 \\
Number of motorised vehicles per household & \\
Reside within the inner city boundary of BMA and within Greater & $44.90 \%$ and $37.90 \%{ }^{1}$ \\
BMA &
\end{tabular}

Trips engagements and travel time spent on weekdays (weekends) ${ }^{2}$ :

Number of trips

Number of trip chains

$2.64(2.29)$

$1.26(1.08)$

Percentage of using motorised mode

$39.19 \%(36.77 \%)$

Percentage of using public transport

$14.88 \%(9.55 \%)$

Percentage of using non-motorised mode

$34.49 \%(32.08 \%)$

Total travel time spent from Monday-Friday (minutes)

$74.87(69.35)$

Time spent for different activities on weekdays (weekends) ${ }^{2}$ :

Time spent for in-home mandatory activities (minutes)

$693.17(738.18)$

Time spent for in-home leisure \& maintenance activities (minutes)

$308.23(363.09)$

Time spent for working/school activities (minutes)

$298.85(161.99)$

Time spent for out-of-home grocery shopping (minutes)

$13.11(21.62)$

Time spent for out-of-home social-recreational (minutes)

$51.72(61.52)$

Time spent for out-of-home other maintenance and sport (minutes)

$5.04(24.75)$

Percentage of time engaging with multi-tasking activities within certain activity on weekdays (weekends) ${ }^{2}$

Percentage of time engaging with multi-tasking activities within travel activities

$6.89 \%(5.22 \%)$

Percentage of time engaging with multi-tasking activities within out-ofhome mandatory activities

$7.11 \%(3.64 \%)$

Percentage of time engaging with multi-tasking activities within out-ofhome discretionary activities

$17.84 \%(11.85 \%)$

Built environment variables ${ }^{3}$ :

Density of population per square-km

11332.02

Density of industrial and government office area per square-km within the respondents' residential location

0.10992

$\mathrm{Km}$-length of road and railway per square-km within the respondents' residential location

38.57 and 4.83

Perceived neighbourhood conditions

Perceived to have good neighbours within a neighbourhood 


\begin{tabular}{|l|c|}
\hline \multicolumn{1}{|c|}{ Variables } & $\begin{array}{c}\text { Percentage or } \\
\text { Mean }\end{array}$ \\
\hline $\begin{array}{l}\text { Perceived to live within a neighbourhood with good access to public } \\
\text { amenities }\end{array}$ & 3.51 \\
Perceived to live within a neighbourhood with good physical conditions & 3.58 \\
$\begin{array}{l}\text { Perceived to live within a neighbourhood with good transportation } \\
\text { networks and performances }\end{array}$ & 3.32 \\
\hline
\end{tabular}

Note: Trip chain is defined as home to home trip.

1 The remaining is students (25.31\%), part of high income households (8.90\%) and reside within CBD of BMA $(17.20 \%)$

2 The values in brackets show the percentage/mean values on weekends, otherwise is on weekdays

3 The density is calculated based on built area in only horizontal plane in $\mathrm{km} 2$ divided by total area in $\mathrm{km} 2$. The measurement is excluded the area on vertical plane

4 Following the definition of density of certain built area, living in a denser settlement area does not always mean to live in a populated area. More populous area can mean an area which contains low density settlement area in horizontal plane (but denser in vertical plane).

\section{Proposed Model Structure}

This study tries to explore interactions among temporal, social, spatial and health elements of individuals within time-space perspective in explaining or understanding individuals' daily and global well-being. Built environment and perceived accessibility were also included in the analysis to show interaction with the environment and individual perception toward environment [18]. Figure 3 shows the proposed model used in this study. This study also includes nesting effects of individuals' day-to-day activity-travel behaviour variability. In social science research, hierarchical nesting observations (such as day-to-day variability effect) should be considered to better capture individuals' behaviour instead of mutual independent observations [11, 19]. Individuals' activity-travel behaviour is subject to individuals' daily activity-travel behaviour and other household members' activity behaviours. The inclusion of day-to-day effects will estimate better parameters to understand the relationship among temporal, social, spatial and health variables within time and space perspective in explaining individuals' daily and global well-being. Estimating better or nonbias parameters may lead to recommend better policy implications in our society.

In order to include hierarchical nesting observations such as day-to-day variability and other household members' activity-travel participation effects, a hierarchical SEM was used in this study. A hierarchical SEM captured the complexity of mechanisms of relationship between daily and global well-being in a recursive structure while accounting for the day-today variability effect of individuals' time-space constraints. The method was not expected to deal with any reciprocal effect. The coefficients of parameters $(\beta \mathrm{n}$ and $\gamma \mathrm{n})$ in the hierarchical SEM took into account day-to-day variations in endogenous activity-travel patterns and exogenous variables made by individual i on day t. The uncorrelated individual specific error term (un, for $n=1-4$ ) has a mean value of zero and variance of $\sigma u$, while $\varepsilon n$ (for $n=1-4$ ) is the uncorrelated combined time and individual error components with a mean value of zero and variance of $\sigma \varepsilon$. The individual specific error term captured the unobserved heterogeneity amongst individuals which was not explained by their day-to-day variations in activity-travel pattern variables. The coefficients of parameters $(\beta n$ and $\gamma \mathrm{n})$ were estimated by modified OLS or Generalised Least Square (GLS) [20]. GLS was selected to produce an uncorrelated estimation between individual specific error terms, and combined time and individual error components. The GLS also yields independent estimations between those error terms and endogenous and exogenous variables to produce unbiased, consistent, efficient and asymptotically normal estimations for this purpose [20,21]. 


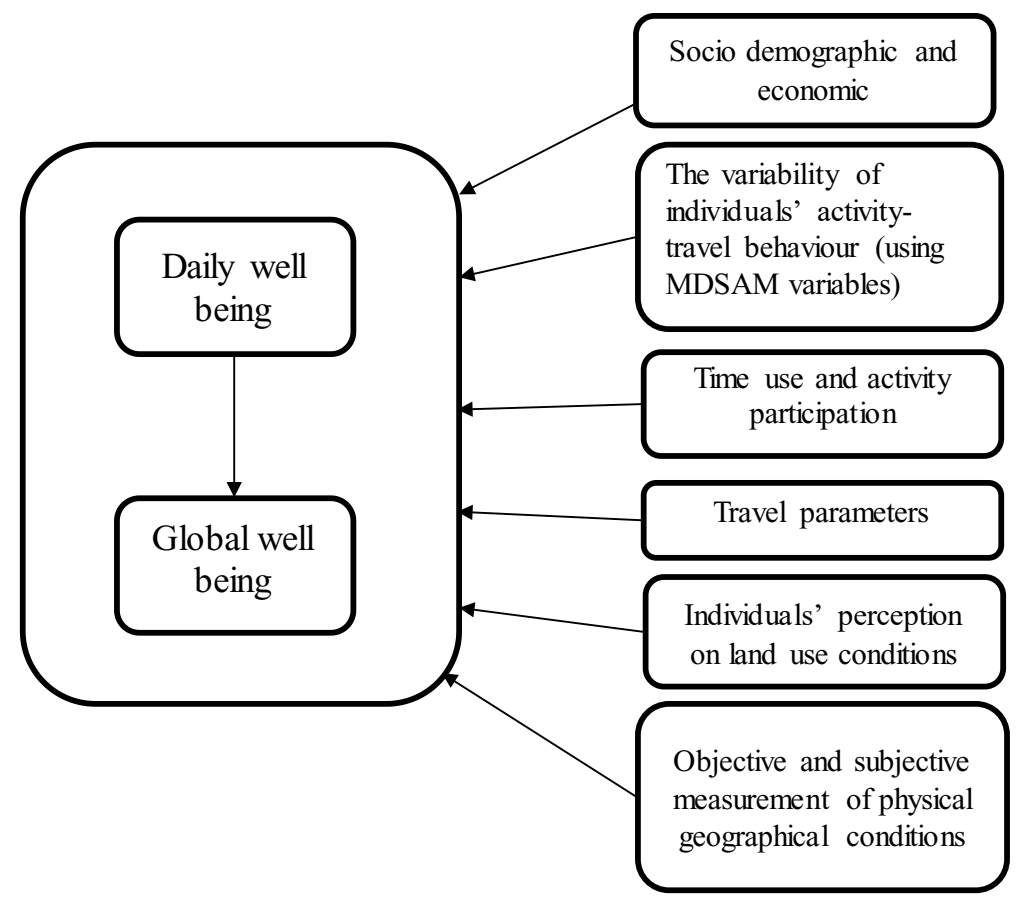

Fig.1 Proposed model structure

To more clearly show the model in Figure 1, with mathematical forms, Equations 1 were written as follow:

Daily Well-beingi, $\mathrm{t}=(\alpha \mathrm{i}+\mathrm{ui})+\beta 1 \mathrm{Wi}+\beta 2 \mathrm{Ri}+\beta 3 \mathrm{Hi}+\beta 4$ Time-Acti.t $+\beta 5$ Traveli.t + $\beta 6$ MDSAMi.t $+\beta 7$ Multitaski.t+ $\varepsilon$ i,

Global Well-being or Life Satisfactioni, $\mathrm{t}=(\alpha \mathrm{i}+\mathrm{ui})+\gamma_{1}$ Dally $\widehat{W e l l}-$ being $_{l . t}+\beta 1 \mathrm{Wi}+$ $\beta 2 \mathrm{Ri}+\beta 3 \mathrm{Hi}+\beta 4$ Time-Acti.t $+\beta 5$ Traveli.t $+\beta 6$ MDSAMi.t $+\beta 7$ Multitaski.t $+\varepsilon \mathrm{i}, \mathrm{t}$

Linier and non-linier mixed effect models or NLME package was used to apply two level multilevel modelling in this study [20]. The coefficient parameters in NLME were estimated by maximum likelihood estimator as shown in general by equation $2[22,23]$. The idea of hierarchical nesting is to find parameters $\sum_{b}$ which are shared among observations within a nested group. The parameter $\sum_{b}$, then used to jointly estimate parameter $\beta$. It means that regression parameter $\beta$ is estimated with including variations of nested observations which in this study are individuals' day-to-day and other household members' activity-travel behaviour variability effect.

$$
L^{*}\left(\sum_{b}, \beta ; y\right)=\int\left(P ( y | \beta , b , i ) \left(P\left(b \mid \sum_{b}\right) d b\right.\right.
$$

The advantage of this model compared to certain path analysis method (e.g FIML) is that it can deal with categorical variables. Moreover, the model needs less computational time compared to multilevel path analysis models. However, it is inefficient when estimating the relationships between latent variables and hierarchical nesting observations. 


\section{Estimation Results}

Table 2 shows that how life circumstance variables represented by socio-demographic variables are not found to significantly people's life satisfaction $[1,12,13]$. Only few of life circumstance variables significantly influence individuals' daily subjective well-being. Only few of time-space variables such as daily travel parameters, time-use and activity participation and multitasking activities, and socio demographic are found to significantly shape people's life satisfaction. It is presumably because almost all time-space variables are represented by individuals' daily subjective well-being that positively shape people's life satisfaction.

As hypothesised earlier, individuals' daily time and space constraints represented by people's daily travel parameters, time-use and activity participation, and multitasking activities shape their daily subjective well-being, whereas no time-space variables influence individuals' life satisfaction. Spending more time to discretionary activities is found to make people has better daily subjective well-being. Moreover, recording multitasking activities in time-use survey shows that undertaking passive leisure activities as secondary activities such as watching TV or socializing with other people within in-home mandatory and out-of-home discretionary activities tend to positively shape individuals' daily subjective well-being. In conjunction with this, household income and person's access to motorised mode are the only socio-demographic variable that shape individuals' daily subjective well-being. Better income and access to motorised mode may be correspond with having more opportunities to engage in discretionary activities $[8,10]$.

Travel parameters are found to significantly influence daily subjective well-being, whereas only trip chaining variable significantly shape individuals' life satisfaction. Undertaking more trip chaining tend to be corresponded with visiting more activity locations for participating out-of-home leisure activities [10, 24, 25]. Therefore, undertaking more trip chaining tend to be correlated with having better daily and global subjective well-being. The results also show that having more percentage of using motorised and public transport are found to reduce individuals' daily subjective well-being.

Integration of individuals' daily activity-travel behaviour and travel parameters in the model may make only few subjective and objective geographical variables that significantly influence daily and global well-being. Residing within an area with denser industrial and government office may correspond with residing within less dense area in BMA [26, 27]. Living within less dense area and with bad physical conditions tend to be negatively correlated with having worse daily subjective well-being $[2,26]$. Perceived to live within good neighbourhood tends to positively correlated with having better life satisfaction.

Table 2 also exhibits how another individuals' domain well-being such as health variables positively shape individuals' daily and global well-being [1, 2]. Having no mental problems for last 4 weeks tend to shape individuals' daily subjective well-being, whereas having better social health tend to shape someone's life satisfaction.

Table 2. Estimation results

\begin{tabular}{|l|c|c|c|c|}
\hline \multirow{2}{*}{ Variables } & \multicolumn{2}{c|}{$\begin{array}{c}\text { Daily subjective well- } \\
\text { being }\end{array}$} & \multicolumn{2}{c|}{$\begin{array}{c}\text { Global subjective well- } \\
\text { being }\end{array}$} \\
\cline { 2 - 5 } & $\begin{array}{c}\text { Coefficient } \\
\text { s }\end{array}$ & T-stat & $\begin{array}{c}\text { Coefficient } \\
\text { s }\end{array}$ & T-stat \\
\hline Intercept & 0.12757 & 0.5747 & 0.16342 & 0.001 \\
\hline $\begin{array}{l}\text { Having better daily subjective well- } \\
\text { being }\end{array}$ & & & 0.04628 & 0.001 \\
$\begin{array}{l}\text { The average variability of } \\
\text { individuals' members' activity-travel } \\
\text { patterns }\end{array}$ & & & -0.00031 & 0.001 \\
\hline
\end{tabular}




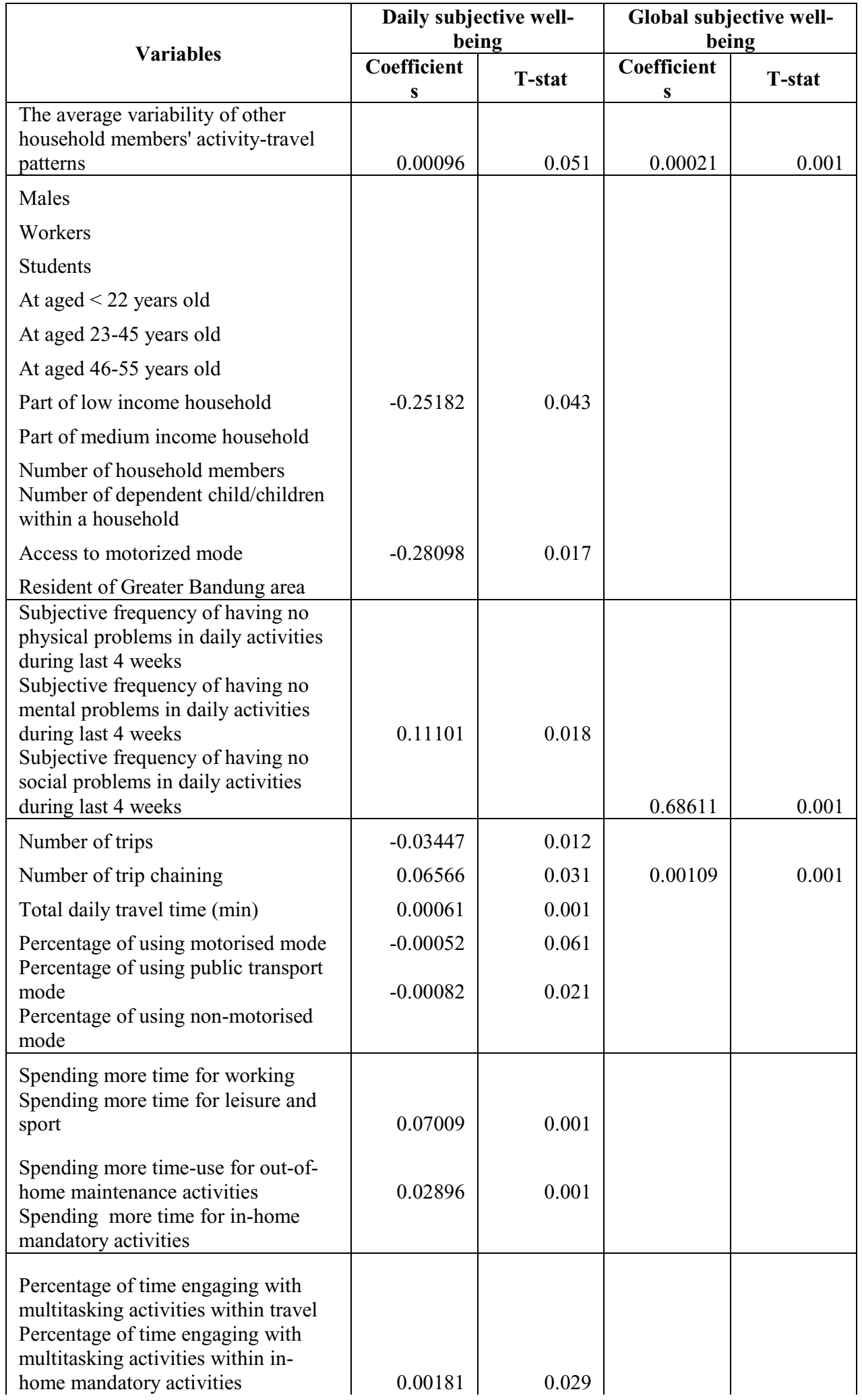




\begin{tabular}{|c|c|c|c|c|}
\hline \multirow{2}{*}{ Variables } & \multicolumn{2}{|c|}{$\begin{array}{c}\text { Daily subjective well- } \\
\text { being }\end{array}$} & \multicolumn{2}{|c|}{$\begin{array}{c}\text { Global subjective well- } \\
\text { being }\end{array}$} \\
\hline & $\begin{array}{c}\text { Coefficient } \\
\text { s }\end{array}$ & T-stat & $\begin{array}{c}\text { Coefficient } \\
\text { s }\end{array}$ & T-stat \\
\hline $\begin{array}{l}\text { Percentage of time engaging with } \\
\text { multitasking activities within in- } \\
\text { home discretionary activities } \\
\text { Percentage of time engaging with } \\
\text { multitasking activities within out-of- } \\
\text { home mandatory activities } \\
\text { Percentage of time engaging with } \\
\text { multitasking activities within out-of- } \\
\text { home discretionary activities }\end{array}$ & 0.00049 & 0.027 & & \\
\hline $\begin{array}{l}\text { Density of population per square-km } \\
\text { Density of industrial and government } \\
\text { office area per square-km within the } \\
\text { respondents' residential location } \\
\text { Km-length of road and railway per } \\
\text { square-km within the respondents' } \\
\text { residential location }\end{array}$ & -0.11434 & 0.001 & & \\
\hline $\begin{array}{l}\text { Perceived to live within good } \\
\text { neighborhood } \\
\text { Perceived to live surrounded by good } \\
\text { amenities within neighborhood } \\
\text { Perceived to live within a } \\
\text { neighborhood with good physical } \\
\text { conditions } \\
\text { Perceived to live within a } \\
\text { neighborhood with good } \\
\text { transportation network and } \\
\text { performance }\end{array}$ & 0.12856 & 0.001 & 1.61158 & 0.001 \\
\hline Mean of dependent variables & \multicolumn{2}{|c|}{-0.01981} & \multicolumn{2}{|c|}{0} \\
\hline $\begin{array}{l}\text { Standard deviation of dependent } \\
\text { variables }\end{array}$ & \multicolumn{2}{|c|}{0.99288} & \multicolumn{2}{|c|}{0.99999} \\
\hline$\varepsilon_{i t}$ & \multicolumn{2}{|c|}{0.27618} & \multicolumn{2}{|c|}{0.00019} \\
\hline$u_{i}$ & \multicolumn{2}{|c|}{0.58008} & \multicolumn{2}{|c|}{0.93915} \\
\hline Number of Observations $(N)$ & \multicolumn{2}{|c|}{11578} & \multicolumn{2}{|c|}{11592} \\
\hline R-square & \multicolumn{2}{|c|}{0.13441} & \multicolumn{2}{|c|}{0.06147} \\
\hline Log Likelihood & \multicolumn{2}{|c|}{-15509.65} & \multicolumn{2}{|c|}{-16080.11} \\
\hline
\end{tabular}

\section{CONCLUSSION}

Using a hierarchical SEM and multidimensional 3-week household time-use and activity diary, this study investigated how interaction of individuals' time-space variables such as daily travel parameters, time-use and activity participation and percentage of undertaking passive leisure within various activity participation, socio-demographic, and objective and subjective geographical conditions shape individuals' daily and global subjective well-being. 
This study also tested whether individuals' time-space variables shape people life satisfaction through daily subjective well-being variable or not.

This study confirms that life circumstances insignificantly shape people's well-being [1, $12,13]$. Moreover, daily subjective well-being or people daily context in which contains how people organizes their daily activity-travel behaviour positively shape people life satisfaction as hypothesised. Daily subjective well-being is a representation individuals' daily timespace variables in which indirectly shape people's life satisfaction. This study also confirms that different daily activity participation tends to shape different level of people's daily subjective well-being. Spending more time-use for leisure, sport and grocery shopping tends to positively correlate with having better daily subjective well-being. Moreover, having better income and more access to motorised mode tend to make individuals to have more opportunities to engage with out-of-home discretionary activities.

Moreover, another domain well-being such as people health performance is found to positively shape people's daily and global well-being [1,2]. Better health in term of better mental and social may correspond with having better daily and global well-being, respectively.

For policy implementations, this study can say that providing more opportunities for undertaking out-of-home activities such as out-of-home leisure, sport and grocery shopping with time-use policy [10] and denser land use planning [26, 28, 29, 30] tend to be correlated with better daily well-being. In BMA case, time-use policy may correspond with reducing travel time policy as argued in previous studies [10, 27]. Moreover, living with good neighbours make people to have better life satisfaction.

\section{References}

1. Kahneman, D., Krueger, A. B., Schkade, D. A., Schwarz, N., Stone, A. Science 306, 5702 (2004)

2. Schwanen, T., Wang. D. Association of American Geographers 104, 4 (2014)

3. Baron. N. (2005). Adjusting the volume: In-place and mobile dimensions of discourse control through technology. Proceedings of Mobile Communication and the Network Society. Rutgers University, USA

4. Ettema, D., Gärling, T., Olsson, L. E., Friman, M. Out-of-home activities, daily travel and subjective well-being. Urban Geography 32, 6 (2010).

5. Rasouli, S., Timmermans, H. Transportation Research Part A 63 (2014).

6. Friman, M., Gärling, T., Ettema, D., Olsson, L. E. Transportation Research Part A 106 (2017).

7. Yamamoto, T., Kitamura, R. Transportation 26 (1999)

8. Kang H., Scott D.M. Transportation Research part A 44 (2010)

9. Dharmowijoyo, D.B.E., Susilo, Y.O., Karlstöm, A. Environment and Planning B 41 (2014)

10. Dharmowijoyo, D.B.E., Susilo, Y.O., Karlstöm, A. Journal of Transport Geography 54 (2016)

11. Schwanen, T., Kwan. M.P., Ren. F. Geoforum 39 (2008)

12. Brickman. P., Campbell, D. T. in Adaptation-level theory, (Academic Press, New York, 1971)

13. Easterlin, E. A. Journal of Economic Behaviour and Organization 29 (1995)

14. Dharmowijoyo, D.B.E., Susilo, Y.O., Karlstöm, A. Transportation Research Part A 80 (2015)

15. Cullen, I.G., Godson, V. Progress in Planning 4 (1975) 
16. Kenyon. S. International Journal of Time Use Research 7 (2010)

17. Circella, G., Mokhtarian, P.L., Poff. L.K. International Journal of Time Use Research 9 (2012)

18. Paccione, M. Landscape and Urban Planning 65 (2003)

19. Snijders, T.A.B., Bosker A.J. Multilevel Analysis: An introduction to basic and advanced multilevel modelling (Sage. London, 1999)

20. Gujarati, D. Basic Econometric (McGrawHill. Boston, 2003)

21. Hansen, C.B. Inference in linier panel data models with serial correlation and an essay on the impact of 401(k) participation on the wealth distribution. PhD Dissertation. (Massachusetts Institute of Technology, 2004)

22. Pinheiro J, Bates D, DebRoy S, Sarkar D and R Core Team nlme: Linear and Nonlinear Mixed Effects Models. R package version 3.1-131, https://CRAN.Rproject.org/package $=$ nlme $(2017)$

23. Levy, R., Fedorenko, E., Breen, M., and Gibson, T. Cognition 122, 1 (2012)

24. Kitamura, R., Susilo, Y. O. Transportation Research Record 1985 (2006)

25. Dharmowijoyo, D.B.E., Susilo, Y.O., Karlstöm, A. Transportation 43, 4 (2016)

26. Arifwidodo, S.D. City, Culture and Society 3 (2012)

27. Tarigan, A.K., Sagala, S., Samsura, D.A.A., Fisabilillah, D.F.. Simarmata, H.A., Nababan, M. Cities 50 (2016)

28. Ballas, D., Tranmer, M. International Regional Science Review 35, 1 (2012)

29. Berry, B.J.L., Okulicz-Kozaryn, A. Urban Geography 32, 6 (2011)

30. Morrison, P. S. Regional Studies 45, 8 (2011) 